\title{
A EXPERIÊNCIA DO PRIMEIRO CURSO TÉCNICO INTEGRADO EM DANÇA NO BRASIL
}

\author{
Amanda Santos de Lima' \\ Celia Regina Otranto ${ }^{2}$
}

\begin{abstract}
Resumo: o artigo analisa o panorama da profissionalização da dança no Brasil, tomando como referência empírica o processo de implantação e desenvolvimento do Curso Técnico Integrado em Dança da Escola Técnica Estadual Adolpho Bloch (ETEAB). O foco da análise são as especificidades de um curso técnico de dança integrado ao Ensino Médio da rede pública de ensino do Estado do Rio de Janeiro. A partir de depoimentos de professores e fontes primárias, a análise aponta que o Curso Técnico em Dança da ETEAB incorpora a dimensão intelectual ao trabalho produtivo, pois, além do técnico em dança, busca formar trabalhadores cidadãos, concebidos como sujeitos históricos capazes de transformar sua realidade social, tomando o trabalho como princípio educativo. Apesar de algumas dificuldades percebidas no desenvolvimento do Curso, a análise conclui que a formação oferecida é diferenciada devido aos avanços na integração entre formação profissional e formação geral básica.
\end{abstract}

Palavras-Chave: Profissionalização em Dança - Ensino Técnico - Ensino Médio Ensino Integrado - Formação Profissional.

\section{THE EXPERIENCE OF THE FIRST TECHNICAL COURSE INTEGRATED IN DANCE IN BRAZIL}

Abstract: the article analyzes the professional training setup in Dance in dance in Brazil, taking as empirical reference the process of implementation and development of the Integrated Technical Course in Dance of the Escola Técnica Estadual Adolpho Bloch

\footnotetext{
1 Mestre em Educação pela Universidade Federal Rural do Rio de Janeiro (UFRRJ). Atua como professora de Educação Infantil no Colégio Pedro II, Unidade de Educação Infantil Realengo. É pedagoga, formada pela Universidade Federal do Rio de Janeiro, com experiência nas áreas de Dança, Coordenação Pedagógica, Educação Profissional e Educação Infantil. E-mail: amandasantos@hotmail.com

2 Doutora em Ciências Sociais pela Universidade Federal Rural do Rio de Janeiro (UFRRJ), com estágio pósdoutoral em educação pela Universidade Estadual de Campinas (UNICAMP). Atua como professora titular da UFRRJ, onde integra o quadro docente do Programa de Educação, Contextos Contemporâneos e Demandas Populares (PPGEduc) e lidera o Grupo de Estudos e Pesquisas da História da Universidade Rural (GEPHUR). É membro da Rede UNIVERSITAS, vinculada ao GT-11 "Política da Educação Superior" da Associação Nacional de Pesquisa e Pós-Graduação em Educação (ANPEd), do qual é coordenadora. E-mail: celiaotranto@terra.com.br
} 
(ETEAB). The focus of the analysis is the specificities of a technical course on dance integrated into the High School of public net teaching of Rio de Janeiro State. From the teachers' testimonials and primary sources, the analysis points that the Technical Course in Dance of ETEAB incorporates the intellectual dimension to productive work, because, in addition to the dance technician, it seeks to form citizen workers, conceived as historical subjects capable of transforming your social reality, taking work as a pedagogic principle. Despite some difficulties perceived in the development of the Course, the analysis concludes that the training offered is differentiated due to the advances in the integration between professional training and basic general forming.

Keywords: Profissionalising in Dance - Technical Education - High School Integrated Education - Professional Training.

\section{LA EXPERIENCIA DEL PRIMER CURSO TÉCNICO INTEGRADO EN DANZA EN BRASIL}

Resumen: el artículo analiza el panorama de la profesionalización en la danza en Brasil, tomando como referencia empírica el proceso de implementación y desarrollo del Curso Técnico Integrado de Danza de la Escuela Técnica Estadual Adolpho Bloch (ETEAB). El enfoque del análisis son las especificidades de un curso técnico de danza integrado a la formación secundaria en red pública de enseñanza del estado de Río de Janeiro. A partir de depoimentos de docentes y de fuentes primarias, el análisis señala que el Curso Técnico de Danza de ETEAB incorpora la dimensión intelectual al trabajo productivo, ya que, además del técnico de danza, busca formar trabajadores ciudadanos, concebidos como sujetos históricos capaces de transformar su realidad social, tomando el trabajo como principio pedagógico. A pesar de algunas dificultades percibidas en el desarrollo del Curso, el análisis concluye que la formación ofrecida se diferencia por los avances en la integración entre la formación profesional y la formación general básica.

Palabras clave: Profesionalisación en danza - Educación Técnica - Escuela Secundaria - Educación Integrada - Capacitación Profesional.

\section{Introdução}

A luta por um espaço digno para a dança na educação não é tão recente, seja dentro ou fora do espaço escolar. Desde as primeiras escolas de dança e corpos de baile, criados para a disseminação do ensino de dança em ambientes diversos que acabaram se constituindo nos primeiros cursos profissionalizantes, até o surgimento dos cursos superiores de bacharelado e licenciatura, e, agora, com a chegada do primeiro curso técnico em dança integrado ao Ensino Médio no país (FAETEC, 2011), tal linguagem artística vem conquistando seu lugar e construindo um histórico, no mínimo, interessante.

A dança não é apenas atividade das classes nobres da burguesia, mas das mais variadas classes socioeconômicas. Porém, a exemplo dos cursos técnicos de dança 
oferecidos no Rio de Janeiro, foi possível perceber que a classe que mais tem acesso ao estudo profissionalizante desta linguagem artística, tanto no passado quanto no presente, não está entre as menos favorecidas economicamente, a não ser por meio da oferta de bolsas de estudo, o que não compreende a maior parcela do público. 0 ensino de dança hoje é contemplado na área educacional de diversas formas e em ambientes distintos - escolas regulares, projetos sociais, academias, escolas de dança, são exemplos de instituições que trabalham com o ensino de dança de diferentes maneiras e com deversificadas finalidades educacionais, culturais e artísticas.

0 terceiro setor vem se destacando na abertura de espaços para o ensino e apreciação da dança, se constituindo, na atualidade, como um dos mais promissores mercados de trabalho para os profissionais da dança. Strazzacappa (2009) ressalta que ainda são escassos os concursos nas redes públicas e as contratações na rede privada para professores de dança, destacando então a importância das escolas de dança para os profissionais da área, como também para os que querem estudar e/ou praticar dança. É muito comum que alunos recém-formados em cursos profissionalizantes ou não de escolas de dança se tornem professores na própria escola ou de outras. Vale destacar que, apesar de muitas escolas de dança empregarem bailarinos para dar aulas de dança sem que estes tenham a habilitação adequada, somente a licenciatura em dança forma professores de dança.

Nas escolas de dança, em geral, predomina o ensino do balé clássico, frequentemente acompanhado por outros estilos como jazz, sapateado, dança espanhola, dança afro-brasileira, dança contemporânea, entre outros. 0 ensino ofertado por estas instituições também é algo que merece ser problematizado, pois, conforme salienta Marques (2010, p. 28), "o modo com que a dança é ensinada - ou seja, as metodologias adequadas - podem fazer com que esse potencial da arte da dança seja ou não transformador". Segundo a mesma pesquisadora, é preciso mais do que contatos. $\mathrm{O}$ encontro entre a dança e a educação deve ser dialógico, e para tanto, estabelecer relações, onde "a virtuose, o controle corporal individual, a exigência da perfeição na execução de passos" (MARQUES, 2010, p. 33) não sejam os principais produtos almejados.

Navas (2010) considera um passo fundamental o investimento em escolas públicas de Ensino Médio em arte/dança. Concordando com esta afirmativa e tendo como propósito aprofundar a compreensão e as análises do processo de formação do técnico de nível médio em dança, desenvolvemos a pesquisa ao longo do Curso de Mestrado no Programa de Pós-Graduação em Educação, Contextos Contemporâneos 
e Demandas Populares - PPGEduc - da Universidade Federal Rural do Rio de Janeiro. O estudo teve por objetivo identificar como a integração entre os ensinos médio e técnico, proposta pelo Curso Técnico em Dança da Escola Técnica Estadual Adolpho Bloch, estava acontecendo na prática e até que ponto se aproximava da proposta de superação da dicotomia entre trabalho manual e intelectual e entre educação profissional e formação geral. A pesquisa de campo foi desenvolvida a partir dos seguintes procedimentos metodológicos: observações participantes, entrevistas, aplicações de questionários e análise de documentos. As observações participantes se deram no decorrer das aulas de disciplinas de diversas áreas abordadas no currículo do curso em questão, como também nas reuniões pedagógicas. As entrevistas foram feitas com os seguintes profissionais da Escola: coordenadora do Curso Técnico em Dança, diretor da Escola Técnica Estadual (ETE) Adolpho Bloch e supervisora pedagógica do Departamento de Desenvolvimento da Educação Básica e Técnica (DDE) da Fundação de Apoio à Escola Técnica (FAETEC). Os questionários foram aplicados ao corpo docente e discente. A análise de documentos foi direcionada, principalmente, para os seguintes documentos: plano de curso, grade curricular, ementas das disciplinas oferecidas, textos e materiais pedagógicos utilizados pelos professores.

Neste artigo buscamos trazer informações e provocar reflexões sobre como está se desenvolvendo o ensino de dança em diferentes instituições educacionais e, mais especificamente na educação profissional; apresentar um panorama da profissionalização em dança no Rio de Janeiro; e caracterizar a formação encontrada no curso técnico em dança integrado ao Ensino Médio da Escola Técnica Estadual Adolpho Bloch destacando seus diferenciais.

\section{A Profissionalização em Dança}

Das profissões reconhecidas pela sociedade contemporânea, as que são ligadas às artes são as menos estudadas (COLI, 2006). Há uma visão idealizada de "vocação" do artista, que colabora para a ocultação dos aspectos reais da carreira que "exige um árduo processo de disciplina [...], além do conhecimento de cultura geral" (COLI, 2006, p. 168). A formação do bailarino demanda tempo, dedicação, restrições, e requer um grande investimento inicial que deve acompanhá-lo em toda a sua formação.

A formação técnica de nível médio é um dos caminhos para a formação do artista da dança, mas não o único. Portanto, para além das escolas regulares e das escolas 
de dança, que dispõem de determinados tipos de formação, os artistas se formam profissionalmente de outras maneiras:

As escolas, estúdios, academias têm como papel principal iniciar e propiciar a formação técnica e artística do futuro profissional da dança. Em geral, os estudantes de dança perfazem um percurso de estudos não sistematizados (pensemos numa estrutura curricular), ou sistematizados em métodos de formação específica relativos a uma determinada técnica, desenhados por graus de crescente complexidade. Aqui, como diria Strazzacappa (2003), as relações mestre-discípulo, artista-aprendiz caracterizam o aprendizado e são marcantes no memorial de cada um dos artistas. Seguramente, podemos afirmar que a maioria dos artistas da dança ainda desenvolve seus estudos e chega à profissionalização por essa via (TERRA, 2010, p. 73).

Em decorrência desta escassez de cursos técnicos de nível médio na área de dança, a profissionalização, neste nível, encontra outros caminhos para se efetivar, ocorrendo a validação desse processo por meio de sindicatos, que, segundo a avaliação de Terra (2010, p. 73), “sem diretrizes ou parâmetros norteadores não se encontram preparados para avaliar habilidades, atitudes e competências requeridas aos diferentes artistas da dança". Para obtenção de um registro na Delegacia Regional do Trabalho (DRT) como artista, há três formas:

Segundo a Lei no 6.533/78, consideram-se três possíveis percursos de profissionalização:

- Após anos de estudos realizados no ensino não formal, nos chamados cursos livres e/ou de formação não reconhecidos pelo MEC (estúdios, academias, escolas, projetos, centros de formação), articulando-os as experiências de participação em apresentações e produções artísticas, o aspirante à artista da dança poderá obter seu registro profissional - o DRT - junto aos SATEDs (Sindicatos dos Artistas e Técnicos em Espetáculos de Diversões) e SINDIDANÇAs (Sindicatos de Dança, casos de São Paulo e Rio de Janeiro);

- Um outro percurso é realizar a formação num Curso Técnico ( $2^{\circ}$ grau) reconhecido pelo MEC e/ou pelas Secretarias Estaduais de Educação, os quais fornecem um diploma que levará o aluno a obter o DRT;

- Por último, tal percurso pode ser realizado num Curso de Graduação em Dança (3ํำ grau); considerado também como ensino formal por ser totalmente fiscalizado pelo MEC; mediante o diploma de Bacharel em Dança o aluno realiza também seu registro profissional como dançarino na Delegacia Regional do Trabalho (TERRA, 2010, p. 72).

Como podemos verificar, os cursos superiores em dança são relativamente recentes. Por este motivo, e pela formação em dança acontecer muito comumente por outras vias que antecedem a formação universitária, diferente do que ocorre em outras profissões, "muitos dos alunos já chegam formados aos cursos, constituindo- 
se em profissionais-alunos" (NAVAS, 2010, p. 59). No entanto, a dupla jornada de trabalho, tão comum no meio artístico, acaba influenciando na desistência de muitos jovens pela profissão/carreira. 0 fato, de acordo com Coli $(2006$, p. 37),

denota a situação instável e flexível das profissões ligadas às artes [...] Isto seria aprofundado em nossos dias, com as mudanças no mundo do trabalho em geral resultantes do processo de acumulação flexível do capital, especialmente depois de 1990.

É fundamental a compreensão de que o exercício da profissão de bailarino apresenta a particularidade, assim como no caso de muitos atletas, de ser uma carreira voltada para o jovem, pois começa a se constituir, muitas das vezes, quando os estudantes ainda são crianças e adolescentes. As oportunidades como bolsas de estudo no exterior e ingressos em companhias profissionais brasileiras e estrangeiras, se dão desde muito cedo.

Entendendo a necessidade desta formação "precoce", temos de pensar na qualidade de seu oferecimento. Conforme apontado por Navas $(2005$, p. 36 apud TERRA, 2010), faz-se cada vez mais necessária a regulamentação do ensino da dança, através da formulação de leis, que articulem "fiscalização, validação, reciclagem e manutenção de formações de qualidade". Pensemos, portanto, na formação profissional que pode ser oferecida a estes jovens: a formação profissional de nível médio através de cursos técnicos em dança.

\section{A Formação Técnica de Nível Médio em Dança no Rio de Janeiro}

Compartilhamos da mesma curiosidade que Ferreira (2010, p. 79), que traz a seguinte reflexão:

É extremamente curioso porque em nosso país, onde povo tem a dança como um componente forte da sua cultura, e de onde, o mundo profissional da dança internacional reconhece, saem tantos e tão bons bailarinos, há tão poucos Cursos Profissionais de Nível Técnico em Dança, cerca de dezoito inscritos no Cadastro Nacional de Cursos de Educação Profissional Técnica de Nível Médio (CNCT).

Foi, exatamente, esta curiosidade que nos impeliu a pesquisar o assunto, buscando saber o número de escolas no local que elegemos para a pesquisa. Segundo o Sindicato dos Profissionais da Dança do Rio de Janeiro, até 2010, existiam em todo o estado do Rio de Janeiro, somente cinco escolas de dança com oferta de cursos de formação profissional. São elas: Escola Estadual de Dança Maria Olenewa, Escola de Dança Petite Danse, Ballet Dalal Achcar, Escola Angel Vianna e Centro de Dança Rio. 
Dentre as citadas, somente a Escola Estadual de Dança Maria Olenewa é uma instituição pública, e nenhuma delas é uma escola regular, de educação básica.

No ano de 2011, finalmente foi implantado o primeiro curso técnico em dança integrado ao Ensino Médio, oferecido pela Escola Técnica Estadual Adolpho Bloch (ETEAB). Diante da implantação deste curso e do crescimento dos cursos superiores (graduação e pós-graduação) na área, fomos levadas a acreditar que tal formação já não está mais sendo mantida na informalidade e vem avançando significativamente tanto quantitativa quanto qualitativamente. No entanto, isso não significa que não permanecem questões a serem discutidas, pois, se levarmos em consideração somente a formação técnica de nível médio, há muito a ser debatido, conforme apontado abaixo, por Ferreira (2010, p. 81):

\begin{abstract}
Voltemos à questão da formação do bailarino através desses cursos. Será que, se forem formados apenas de um elenco de conteúdos de técnica de dança, mais algumas outras de caráter complementar, mais um corpo docente experiente (formado principalmente por ex-bailarinos), mais uma seleção rigorosa com base na técnica de dança proposta, estarão preparados para as novas propostas da educação? Será que assim não estarão visando só o mercado de trabalho? Será que estarão preparando os bailarinos para assumir seus novos papeis no mundo da dança?
\end{abstract}

Com o propósito de definir o Técnico de Dança, consultamos o Catálogo Nacional de Cursos Técnicos (CNCT). De acordo com este documento, o Técnico em Dança é aquele que:

Desenvolve atividades ligadas à criação e execução de dança, atuando como bailarino, dançarino, diretor ou assistente de palco e contrarregra. Domina os diferentes gêneros e estilos de dança. Emprega técnicas de dança e recursos de improvisação, em espaços cênicos, como formas de expressão corporal (BRASIL, 2012a).

Conforme assinalado anteriormente, existem somente cinco escolas de dança que oferecem cursos técnicos na área de dança no estado, além da primeira escola de educação básica a oferecer tal formação de maneira integrada - todas localizadas no município do Rio de Janeiro, não havendo oferta de educação profissional em dança fora da capital do estado. Neste momento, nos detendo nas cinco primeiras, a questão que se coloca é: a formação que está presente nas escolas de dança que oferecem formação profissional na área seria voltada para a autonomia ou para a adaptação? Ou seja: Os alunos teriam uma verdadeira formação cultural ou uma semi-formação? De acordo com os dados que puderam ser levantados, apresentamos algumas considerações. 
Conceito central na obra de Theodor Adorno, teórico da Teoria Crítica, a cultura ou a formação cultural (Bildung) apresenta um duplo caráter, podendo apontar para a autonomia ou para a adaptação (NOGUEIRA, 2006). O problema, conforme aponta Nogueira (2006, p. 93), é que "por vezes, esse duplo caráter é negado e a faceta da adaptação passa a ser hegemônica, trazendo com isso nefastas consequências para o homem". Ocorre assim, "uma interferência na apreensão da sociedade pelos seus 'sujeitos' pelo mecanismo da 'semiformação': seja com conteúdos irracionais, seja com conteúdos conformistas" (ADORNO, 1995, p. 21).

Esta diferenciação é colocada de forma semelhante também por Paulo Freire, que "tampouco tem a arte/dança como foco de discussão, mas não prescinde em suas reflexões e propostas da educação estética, da 'belezura', diz, necessária à educação crítica e transformadora” (MARQUES, 2010, p. 27). Marques (2010, p. 30), sustentando suas reflexões em Freire, procura apontar a diferença entre contatos e relações. Para a autora, muitas instituições professores "tem trabalhado mais em prol da manutenção do mundo (social, político e cultural/artístico) como ele está do que na tentativa de mudar, alterar, remexer, chacoalhar os cotidianos em que vivemos". Isto seria estabelecer somente um mero contato com a dança e a cultura, contato este que, provavelmente, irá resultar no que Adorno chama de semiformação.

Esta "semiformação" é chamada também de "semicultura" (Halbbildung), se constituindo não como uma etapa que antecede a cultura, mas como um empecilho a esta, pois não passa de uma estratégia burguesa de exercer o domínio através de um consumo não crítico, superficial e, portanto, conformador, não apontando para um processo de crescimento, mas sim reforçando o sentido de alienação (NOGUEIRA, 2006). Segundo Reis (2004, p. 231), para Marx, "o esteticismo exagerado da classe burguesa e o brutal ascetismo da sociedade capitalista compõem as duas faces de uma mesma moeda. Na concepção marxiana, a realidade capitalista é hostil à plenitude do desenvolvimento da capacidade humana de criar".

Assim, torna-se imprescindível o compromisso com uma verdadeira formação cultural, que "precisa levar em conta as condições a que se encontram subordinadas a produção e a reprodução da vida humana em sociedade e na relação com a natureza" (ADORNO, 1995, p. 19). A formação da subjetividade autônoma pela via da educação e da cultura nos parâmetros da sociedade burguesa necessita do apoio de uma crítica objetiva da própria formação social (ADORNO, 1995).

Seguindo a reflexão de Ferreira (2010, p. 83), endosso as perguntas feitas pela autora, se estariam estes cursos: 
preparando alunos capazes de usar suas experiências cognitivas, não apenas na aquisição de destreza e de habilidades técnicas e de repertório de dança, mas também em uma maior compreensão da realidade? Estariam eles prontos não só para reproduzi-la pura e simplesmente, mas para ser capaz de compreendê-la, recriá-la e apropriar-se dela na construção de um novo conhecimento e de um novo ser?

Com exceção da Escola e Faculdade Angel Vianna, que oferece os cursos técnicos de "Bailarino Contemporâneo" e de "Reeducação motora e terapia através do movimento", que têm a finalidade de formar profissionais preparados para o exercício da dança ou para o exercício da terapia através da dança, proporcionando uma visão global do ser humano, com disciplinas como história da dança, técnica teatral, improvisação e prática de montagem (ESCOLA E FACULDADE DE DANÇA ANGEL VIANNA, 2013 - texto em html), os demais cursos, das outras quatro escolas de dança, são centrados em uma formação clássica.

A Escola de Dança Petite Danse, por exemplo, oferece o "Curso Técnico de Bailarino para Corpo de Baile", que apresenta certa diversidade de disciplinas teóricas e práticas (ainda que menor do que a dos cursos da Escola e Faculdade Angel Vianna), porém com predominância do ballet clássico, constituindo um total mínimo de 1.260 horas, incluindo estágio profissional supervisionado, sendo cursado em três anos. Pela avaliação descrita pela escola, podemos pensar sobre os objetivos desta formação:

O aluno deverá ser submetido a um exame de caráter clínico estetoanatômico, e a um exame de seleção físico no qual o candidato deverá demonstrar as suas qualidades inatas e coordenação motora, flexibilidade e musicalidade, sob a responsabilidade e orientação de um professor.

Prova de capacidade técnica relacionada à prática do Ballet Clássico.

O candidato que vier por transferência será submetido também, a uma prova de capacidade técnica para a série que irá cursar. 0 curso técnico será dado nos níveis $1^{\circ}, 2^{\circ}$ e $3^{\circ}$ técnico clássico. (ESCOLA DE DANÇA PETITE DANSE, 2013, - texto em html).

Podemos perceber que a avaliação prioriza elementos relacionados à execução da técnica clássica e ao corpo do bailarino, não contemplando fatores como habilidades e conhecimentos relacionados à criação ou à reflexão crítica.

Tal como a Escola de Dança Petite Danse, o Ballet Dalal Achcar também pretende oferecer uma base clássica sólida, conhecimento diversificado da dança moderna, dança folclórica e outras expressões, assim como conhecimentos musicais, escrita da dança, história da dança, artes plásticas, artes cênicas (cenografia, maquiagem, 
costumes, iluminação) e outros assuntos que o aluno irá acrescentando ao currículo na medida em que for definindo suas tendências, visando diplomar seus alunos como bailarinos profissionais. Nota-se novamente, portanto, a ênfase no ballet clássico e a ausência de conteúdos ligados a uma perspectiva que aponte para a criação, para a autonomia, ao invés da reprodução (BALLET DALAL ACHCAR, 2013 - texto extraído da internet).

Não poderíamos deixar de lado nesta discussão, a primeira escola de dança clássica fundada no Brasil, a Escola Estadual de Dança Maria Olenewa. "As escolas de bailado ou dança, de âmbito público, são espaços institucionais sobre os quais pesa a responsabilidade de uma complexa gama de aspectos sobre o ensino do balé" (MARINHO, 2010, p. 91). Tal escola foi fundada em 1927 e é a única escola de dança pública até hoje que oferece curso profissionalizante, merecendo sua história especial atenção. Vale destacar que a Escola Adolpho Bloch, foco desta pesquisa, não é uma escola de dança, e sim uma escola técnica que oferece o curso profissionalizante de dança.

Em 1975, a então diretora da Escola Estadual de Dança Maria Olenewa, Lydia Costallat, submeteu ao Conselho Estadual de Cultura um Currículo Básico e um Regimento, permitindo ser finalmente a Escola oficializada como Escola Profissionalizante de $2^{\circ}$ Grau pelo Parecer 1937, de 10 de março de 1975, dando a possibilidade de oferecer aos seus alunos um Certificado reconhecido, sem deixar de oferecer cursos não profissionalizantes para diversas faixas etárias. Voltando a pertencer ao Teatro Municipal do Rio de Janeiro em 1995 e após 36 anos funcionando na Lapa, retornou ao Prédio Anexo do referido Teatro em 2013, sendo este fato muito comemorado por toda comunidade docente e discente. Atualmente não se restringindo apenas ao ballet clássico, mas constando do seu currículo várias formas de dança, a escola continua até hoje no seu objetivo principal: o de formar profissionais da dança, através de um curso rigorosamente técnico (EEDMO, 2013 texto extraído da internet).

Segundo reportagem da Revista Veja, centenas de meninas (e alguns meninos) se inscrevem todo ano para ingressar na escola, porém há somente cinquenta vagas para o curso preliminar. Esses candidatos têm de passar por um processo seletivo que avalia características como: flexibilidade, ponta do pé, musicalidade e criatividade. A própria diretora da instituição, Maria Luisa Noronha, destaca que são raros os alunos que chegam a se tornar bailarinos profissionais. (VEJA RIO, 16 de outubro de 2013). "Em 2013, apenas sete jovens receberão o diploma, dos 88 admitidos em fevereiro em diferentes turmas" (VEJA RIO, 16 de outubro de 2013, p. 
36). Tal informação provoca uma reflexão sobre o processo pelo qual esses alunos passam no interior da instituição. É uma rotina rígida, que exige tempo, dedicação, restrições, mas será somente isso? "Na grande sala com pé direito alto, a única voz que seu ouve é a da professora [...] comandando as posições em francês. Focados em cada comando e com semblante sério, os alunos mantêm o silêncio e executam com afinco as determinações" (VEJA RIO, 16 de outubro de 2013, p. 36). Diante dessas informações, cabe questionar: Qual seria o perfil do aluno/bailarino que um curso como este busca? Que profissional quer formar?

É importante ressaltar que não pretendo afirmar aqui que tais cursos não oferecem uma educação de qualidade. Reconhecidos por sua tradição no ballet clássico, em sua maioria, oferecem uma excelente formação técnica para o bailarino. Não se trata de desvalorizar o ballet clássico, até porque "atacar a cultura erudita em nome de uma pretensa defesa da cultura popular é negar às camadas populares o acesso a um patrimônio do qual as elites vêm usufruindo há séculos" (NOGUEIRA, 2006, p. 95). O que se problematiza aqui é a falta de uma base crítica objetiva da própria formação social, entendendo que "é preciso romper com a educação enquanto mera apropriação de instrumental técnico e receituário para a eficiência, insistindo no aprendizado aberto à elaboração da história e ao contato com o outro não-idêntico, o diferenciado" (ADORNO, 1995, p. 27).

Ferreira (2010, p. 81), através de uma pesquisa entre os quatro primeiros cursos técnicos de formação de bailarinos da cidade do Rio de Janeiro, constatou que:

\footnotetext{
ao todo, do total de formandos nos últimos vinte anos, $3 \%$ trabalha ou trabalhou por um período como bailarino, 35\% dedica-se ao ensino da dança, e 1\% trabalham em áreas ligadas à dança (produção, figurinos, coreografia, etc.), concluindo assim que $61 \%$ dos alunos egressos não trabalham com a dança.
}

Tal constatação instiga ainda mais a reflexão sobre qual o papel da dança na formação deste grande número de jovens que a buscam (FERREIRA, 2010). Até mesmo sobre a formação em nível superior, dados do Instituto Brasileiro de Geografia e Estatística IBGE (1994) informam que "72\% dos formados em curso superior em artes não trabalham neste campo" (VILELA, 2010, p. 118). Cursos de educação profissional em dança deveriam se repensar para que o aluno seja capaz de compreender que "o ensinar e aprender daquele momento não são um processo acabado, mas sim um caminho para que outros conhecimentos sejam produzidos, outras conexões sejam estabelecidas e outras ações desencadeadas" (FERREIRA, 2010, p. 81). 
O campo das artes é visto como um campo incerto. "Os artistas sempre viveram na instabilidade, com trabalhos informais e precários" (VILELA, 2010, p. 112). A baixa valorização que se dá à profissão artística, sem dúvida alguma, pesa na escolha do jovem por uma profissão. Assim, muitos bailarinos que vivem a dança desde muito cedo, acabam tomando um rumo profissional que não a contempla. Pode-se perceber então, o "quão difícil é para o artista da dança se inserir como trabalhador em um contexto social mais amplo" (VILELA, 2010, p. 107). Daí o desafio que se coloca para as instituições que formam tais profissionais, dos quais será exigido "o domínio de certas especialidades (técnicas, por exemplo) e, ao mesmo tempo, a multiplicidade; a capacidade de trânsito e articulação entre saberes técnicocriativos, sensíveis e inteligíveis" (TERRA, 2010, p. 74).

Estariam os cursos técnicos das escolas de dança abordados aqui, tal como questiona Marques (2010, p. 30),

\begin{abstract}
satisfeitos com a fome, com as epidemias, com o aquecimento global, com os conflitos religiosos, com a corrupção, com o racismo, com o assédio sexual, com a generalização da violência, com a precariedade dos serviços públicos educacionais, com a insipiência das políticas públicas culturais...? Ou simplesmente nunca pensaram sequer na hipótese de que suas aulas de dança estão - quer queiram ou não - relacionadas às grandes questões e desafios da contemporaneidade?
\end{abstract}

É preciso, segundo a autora, o compromisso dos professores e instituições de educar intérpretes (alunos) criadores, conhecedores de seus corpos, autores de suas danças, singulares em suas atuações - consequentes e posicionados em suas histórias corporais pessoais e coletivas.

A dança enquanto linguagem artística tem o potencial de fornecer lentes diferentes e diferenciadas para conhecermos, desconstruirmos, refletirmos e agirmos sobre os cotidianos multifacetados do mundo em que vivemos. A dança enquanto arte do/com/pelo corpo, quer seja em situação educacional, educativa ou pedagógica carrega em si mesma o potencial de transformação dos cenários cotidianos sociais (MARQUES, 2010, p. 28).

Diante de tais reflexões e constatações, cabe questionar: será que um curso técnico em dança oferecido de forma integrada ao Ensino Médio em uma escola pública de educação básica proporcionaria outro tipo de formação? Esta é uma das perguntas que pretendemos responder com a presente pesquisa. 


\section{o Curso Técnico em Dança da Escola Técnica Estadial Adolpho Bloch}

Um novo curso oferecido pela Escola Técnica Estadual Adolpho Bloch (ETEAB), localizada no bairro de São Cristóvão, na cidade do Rio de Janeiro, constitui-se como o primeiro curso técnico em dança integrado ao Ensino Médio no Rio de Janeiro e o primeiro, entre todos os cursos das mais diversas áreas oferecidos pela FAETEC, com currículo integrado ao Ensino Médio, tendo aberto sua primeira turma em fevereiro de 2011, com 22 alunos.

A escola se constitui como uma unidade privilegiada com cursos ligados à comunicação, possuindo, até o final do ano de 2012, um total de quase 1000 alunos matriculados. Em 2013 todos os cursos iniciaram o ano com currículos integrado, sendo que o curso de dança abriu sua primeira turma em 2011 já de forma integrada, antes de todo esse movimento na rede. Apesar da implantação de currículos integrados se tratar de um movimento atual, verifica-se no Projeto Político Pedagógico da escola de 2004, que dentre os objetivos específicos está o de "valorizar o currículo integrado, trabalhando com conceitos de interdisciplinaridade e contextualização" (ETEAB, 2004, p. 6).

Segundo relato de Rosane Campello, coordenadora do curso, em entrevista realizada em 24 de outubro de 2013, quando a proposta do curso foi apresentada à FAETEC, Márcia Farinazo do Departamento de Educação, lhe contou que haveria a mudança na rede para o ensino integrado e sugeriu que o curso já fosse proposto neste formato. Assim, a proposta inicial, que já apresentava características integradoras, necessitou de alterações e, depois destas, foi aceita.

Segundo Frigotto, Ciavatta e Ramos (2005, p. 44):

O Ensino Médio integrado é aquele possível e necessário em uma realidade conjunturalmente desfavorável - em que os filhos dos trabalhadores precisam obter uma profissão ainda no nível médio, não podendo adiar este projeto para o nível superior de ensino - mas que potencialize mudanças para, superando-se essa conjuntura, constituir-se em uma educação que contenha elementos de uma sociedade justa.

Porém, em muitos outros, o que acontece não é a integração e sim uma justaposição de disciplinas, ou seja, "com aulas isoladas e conteúdos sem diálogo entre si, e principalmente com lugar estabelecido para as disciplinas de formação geral e de formação técnica [...], conservando a dualidade entre o pensar e o fazer" (FEITOSA, 2010, p. 64). Assim, somos levados a perceber que muitos cursos que se 
dizem integrados, na prática funcionam como concomitantes, não havendo, portanto, integração, somente simultaneidade.

Em contrapartida, existem redes e escolas que estão engajadas na construção de cursos que proporcionem uma verdadeira integração entre a formação geral e a formação específica, que na compreensão de Ciavatta (2011, p.6) são aqueles que buscam: "enfocar o trabalho como princípio educativo, no sentido de superar a dicotomia trabalho manual / trabalho intelectual, de incorporar a dimensão intelectual ao trabalho produtivo, de formar trabalhadores capazes de atuar como dirigentes e cidadãos".

Consideramos que o Curso Técnico em Dança da ETEAB, mesmo com os limites que ainda iremos expôr, caminha neste sentido. 0 curso foi aprovado pelo Conselho Estadual de Educação do Rio de Janeiro e publicado no Diário Oficial de 28 de outubro de 2010, se constituindo como o primeiro curso técnico integrado ao Ensino Médio na rede.

O primeiro concurso para o novo curso foi aberto no processo seletivo de 2010, para ingresso em 2011, oferecendo inicialmente vinte vagas. Para o ingresso no curso, não há teste de habilidade específica, pois, segundo a coordenadora Rosane todos podem dançar. Desta primeira turma, com 20 alunos, 18 permaneceram ao longo do ano de 2012 - ano em que foi aberta a segunda turma do curso, com 22 alunos matriculados. Ao iniciar o ano de 2013, 25 novos alunos ingressaram para cursar o $1^{\mathrm{o}}$ ano, tendo o $2^{\mathrm{o}}$ ano 16 alunos e o $3^{\mathrm{o}}$ ano 20 alunos ( 2 alunos foram reprovados, mas continuam no curso), compondo um total de 61 alunos no ano de 2013.

Buscando, principalmente, conhecer o perfil dos alunos do curso, foi aplicado, no mês de maio de 2013, um questionário semiestruturado para $70 \%$ destes (porcentagem correspondente à quantidade de alunos que estavam presentes). Tal instrumento de pesquisa foi validado anteriormente, com participação de três alunos de cada ano de escolaridade. Constatou-se, desta forma, que o curso apresenta alunos de 14 a 20 anos, com um público majoritariamente feminino (86\%). A maior parte do público atendido é oriunda da zona norte do município do Rio de Janeiro e tem como escola anterior uma escola particular. Estes alunos se deslocam se suas moradias até a escola, em São Cristóvão, para estudar de $7 \mathrm{~h}$ até às $15 \mathrm{~h}$, inclusive aos sábados. 
A primeira matriz curricular, aprovada no plano de curso que teve vigência até 2012, tinha a carga horária total de 4.320 horas, na qual a maioria das disciplinas dispunha de 80 horas anuais, podendo ser oferecida em um, dois ou nos três anos, com cada ano totalizando exatamente 1.440 horas. Esta organização inicial sofreu alterações com a diminuição da carga horária total em 38 horas, apresentando atualmente, portanto, 4.282 horas, com cargas horárias diferentes a cada ano. A maior parte das disciplinas que era oferecida com 80 horas anuais, passou a ter 67 horas anuais. A carga horária de Matemática foi aumentada e a carga horária de Língua Portuguesa reduzida. As disciplinas de Informática e Francês não constam mais na matriz atual (embora as aulas de Francês continuem de uma forma alternativa). Sobre a questão da Língua Estrangeira, eram oferecidas aulas de um idioma diferente a cada ano, com a Língua Francesa no primeiro ano, mas segundo exigências da FAETEC, deve haver a oferta de aulas de duas línguas estrangeiras em todos os anos.

O currículo do curso contempla, além das disciplinas da formação geral, aulas de: Técnica de Dança (I, II e III), Consciência Corporal, Fundamentos do Teatro, Fundamentos da Música, Introdução à Dança Contemporânea, História da Dança, Psicologia das Relações Humanas, Dança Contemporânea, Vídeo Dança, Produção Coreográfica, Prática de Montagem, dentre outras. Segundo a coordenadora, as disciplinas oferecidas na organização proposta possibilitam a formação integral do bailarino, que será formado de forma teórico-prática não só para dançar, como também para pensar criticamente o mundo em que vive e desenvolver sua vida profissional com autonomia.

O objetivo geral do curso é desenvolver a formação profissional em Dança de forma integrada e significativa, capacitando para imediata inserção no mercado de trabalho. A expectativa é que, ao término do curso, o aluno esteja capacitado para criar propostas de entretenimento em clubes, associações diversas e espaços culturais, contribuindo para a formação de plateia e aumento da oferta cultural. Existe, ainda, a opção de trabalhar com projetos interdisciplinares e propostas de temas geradores que relacionem a dança com o trabalho, ciência, tecnologia e cultura.

Para tanto, a organização do processo de aprendizagem privilegia a definição de projetos, problemas e/ou questões geradoras que orientam e estimulam a investigação, o pensamento e as ações, assim como a solução de problemas. Dessa forma, "a problematização, a interdisciplinaridade, a contextualização e os ambientes de formação se constituem em ferramentas básicas” (ETEAB, 2013, p.8) 
para a formação pretendida. Com o objetivo de alcançar esta formação integral, caminhos vêm sendo traçados e ações vêm sendo realizadas no âmbito do ensino integrado, que apresenta características interessantes que favorecem uma educação que busca a qualidade, contudo repleta de desafios para a coordenação, corpo docente do curso e direção da unidade, que estão engajadas nessa mudança.

O primeiro ponto é a organização dos componentes curriculares. Os alunos do curso de dança frequentam aulas de disciplina gerais e específicas sem separação por turno ou dia da semana, em horário integral. Mas a simples justaposição de disciplinas gerais e específicas não garante a integração, pois elas podem ocorrer no mesmo turno ou dia, serem ministradas pelo mesmo professor, e ainda assim não dialogarem entre si. Na busca de algo que auxiliasse essa integração entre diferentes áreas do saber, a coordenação do curso organizou cada ano letivo com "temas geradores" ou "binômios", como são chamados pela equipe do curso, de acordo com a coordenadora, ancorados em Edgar Morin e David Ausubel. O primeiro ano trabalha com base nos temas "Corpo" e "Mundo", tendo componentes curriculares como Técnica de dança I (Balé clássico), Língua estrangeira (Francês) e História da dança, que trabalham com conteúdos que possuem um alto potencial de articulação. Já no segundo ano os temas são "Brasil" e "Movimento", enfatizando História do Brasil, danças folclóricas brasileiras, entre outros. E no terceiro ano "Rio de Janeiro" e "Cena" são abordados, contando com disciplinas como "Prática de Montagem", que trabalha com temas ligados à produção cultural e à montagem de um espetáculo, abrangendo assuntos que vão muito além da criação de uma coreografia.

Além desta organização curricular, percebemos a integração entre conhecimentos de diversas áreas nos espetáculos realizados, e também em "no mínimo, duas avaliações, sendo uma por componente curricular e a outra, preferencialmente, interdisciplinar" (ETEAB, 2013, p. 19) por trimestre, buscando que o aluno articule conhecimentos de diferentes áreas para responder as questões. Os alunos também assistem a espetáculos, visitam centros culturais e outros espaços artísticos, também participando de momentos com algum cunho político, como a ocupação do Teatro Cacilda Becker, que é destinado a eventos de dança.

Reuniões quinzenais ou semanais são realizadas para favorecer o trabalho integrado entre professores de disciplinas diversas. Porém, isto é afetado por haver professores se dedicando a até quatro cursos diferentes, em diferentes anos de escolaridade (isto sem considerar a atuação dos professores em outras instituições). O professor que ingressa na rede FAETEC por meio de concurso não se candidata para uma vaga em um determinado curso, mas sim para a unidade. É necessário, 
neste momento, o entendimento da necessidade de uma reorganização voltada para a integração.

Vale ressaltar também que, com salários e plano de carreira melhores do que outras redes e escolas no Rio de Janeiro, a Fundação conta com um corpo docente altamente qualificado, mas que, ainda assim, não tiveram uma formação inicial visando um trabalho docente integrado. Deve-se investir, portanto, em formação tanto inicial quanto continuada, tendo a FAETEC já iniciado um movimento de oferta de seminários e eventos com este propósito.

A partir dos aspectos apresentados, podemos perceber que o Curso Técnico em Dança da ETE Adolpho Bloch apresenta currículo, organização, rotina e objetivos que diferem de outros cursos técnicos em dança, trazendo para o cenário da dança carioca uma nova realidade na formação profissional deste artista. Ao oferecer um curso técnico em dança no mesmo espaço do Ensino Médio, propondo uma formação integrada, a ETEAB passa a abrigar em sua unidade, um curso único, que busca uma formação além da técnica, com disciplinas, atividades e discussões que buscam possibilitar aos alunos uma postura crítica e reflexiva do mundo e da sociedade que irá se refletir em suas produções artísticas, o que sugere a compreensão de um trabalhador integral, entendendo que "não existe trabalho manual puro e nem trabalho intelectual puro" (SAVIANI, 2003, p. 138).

Nosso estudo comprovou que o curso de dança da ETE Adolpho Bloch, proporciona uma formação ampla e diversificada, contemplando em suas atividades disciplinas das mais variadas técnicas de dança, outras que possibilitam o desenvolvimento do potencial criador exigindo improvisações e elaboração de coreografias e cenas, eventos que buscam sensibilizar e envolver a escola como um todo, entre tantas outras ações que fazem deste um curso único.

\section{Algumas Conclusões}

Uma das questões deste estudo foi: “A formação possibilitada por este novo curso, quer em seu formato ou conteúdo, pode ser considerada mais ampla do que a oferecida pelos cursos já existentes nas escolas de dança do Rio de Janeiro?". Pudemos verificar que, em sua maioria, os cursos de tais instituições são centrados no preparo técnico do bailarino e privilegiam a dança clássica (ballet). Já na ETEAB, escola foco desta pesquisa, a formação vai um pouco mais além do preparo meramente técnico. Mesmo havendo justificativas vinculadas ao campo técnico, trata-se de um mecanismo de seleção excludente que valoriza aspectos físicos, 
deixando de lado outros como a capacidade de criação, reflexão e outras características ligadas à expressão corporal, o que indicaria a possibilidade de estarem estes cursos possibilitando somente uma semiformação. Porém, para verificar a fundo tais aspectos seria necessária uma pesquisa mais detalhada, que se dedicasse a estudar mais profundamente o currículo dos cursos destas instituições, adentrando as salas de aula das escolas de dança para uma observação constante de suas práticas, assim como foi feito nesta pesquisa com a ETE Adolpho Bloch.

Além disto, para o ingresso no curso técnico em dança da ETEAB, não é necessária uma seleção específica, somente a prova realizada pelos novos alunos para o ingresso na rede FAETEC, prova esta comum a todos os cursos e baseada em conhecimentos gerais do Ensino Fundamental. 0 curso de dança da ETEAB optou por não selecionar alunos com critérios relacionados a habilidades corporais, inclusive assegurando a matrícula de alunos com necessidades especiais, tendo a justificativa da coordenadora de que a técnica tem que estar à disposição da dança de cada um, e não o contrário. Assim, no curso técnico em dança da ETEAB/FAETEC, são estudados e vivenciados diferentes estilos de dança, buscando fornecer ao aluno o preparo básico em várias linguagens. Desta forma, ele poderá se especializar no estilo que desejar.

Ademais, o curso oferecido pela ETEAB busca formar um profissional que possa atuar como intérprete, criador de danças e gestor de atividades profissionais ligadas à área. Para citar um exemplo, o curso conta com atividades e eventos ao longo do ano oferecendo várias opções que permitem ao aluno aprofundar seus conhecimentos de acordo com seus interesses, através de oficinas de teatro e estilos de dança, que não são contemplados em disciplinas do curso, palestras sobre diversos temas ligados à carreira artística, etc. Além disto, disciplina "Prática de Montagem", cursada pelos alunos do $3^{\circ}$ ano, merece destaque por contemplar diversos conhecimentos sobre a montagem de um espetáculo, não restringindo ao aluno à função de aprender a dançar e coreografar. Ou seja, através deste curso, o aluno adquire conhecimentos que lhe permite uma atuação que vai além da execução e criação de danças. Além de bailarino e coreógrafo, estará preparado para lidar com aspectos ligados a produção cultural como um todo, inclusive com questões burocráticas.

Refletindo sobre as questões abordadas nos parágrafos anteriores, já podemos encontrar diferenciais significativos no curso técnico em dança da ETEAB, tais como: a) Não há seleção baseada em aspectos corporais e habilidades específicas para o ingresso no curso; b) 0 curso contempla diversos estilos de dança, não se 
restringindo a uma técnica específica; c) 0 curso busca alcançar um perfil profissional de intérprete, criador e gestor de atividades ligadas a área de dança, valorizando conhecimentos ligados à produção cultural e à criatividade, transcendendo, portanto, a compreensão do bailarino como executor de danças; d) Não exige alto investimento financeiro como em algumas outras escolas, abrindo, assim, espaço para as classes populares; e) É o único curso técnico em dança existente dentro da rede estadual de educação do Rio de Janeiro e o primeiro da área a adotar o formato integrado ao Ensino Médio na América Latina.

Permanecem dificuldades ligadas à formação inicial e continuada dos professores, e à necessidade de mudanças nas condições de trabalho destes docentes, que vai além da vontade dos professores e da equipe gestora de cada unidade. Acreditamos que para tentar resolvê-lo, primeiramente, seria necessário que, em uma rede onde há cursos técnicos integrados ao Ensino Médio em horário integral, haja também professores em horário integral para viabilizar o trabalho, ou seja, professores com dedicação exclusiva àquela escola, o que não ocorre atualmente. Além disto, mesmo garantindo a dedicação exclusiva à escola, deve-se atentar para a dedicação ao curso, pois o professor não conseguirá atender vários cursos integrados de forma satisfatória, participando de reuniões, realizando planejamentos e atividades em conjunto, etc. A recomendação de que o professor se dedique a um mesmo curso ou eixo já foi feita pela FAETEC através do Departamento de Desenvolvimento da Educação Básica e Técnica (DDE), porém não obteve a adesão esperada nos cursos da rede, até mesmo porque necessita uma compreensão desta necessidade por parte dos professores, que talvez tenha se iniciado com a vivência desta mudança ao longo do ano de 2013. Há também previsão de reformulações na carga horária explicitada no plano de carreiras dos profissionais da rede. Mas, para acompanhar uma possível evolução, seria necessário dar continuidade a este estudo, expandindo a pesquisa a toda a rede FAETEC.

Uma preocupação que surgiu junto com o curso e que se reforça agora em outros cursos da FAETEC, devido à implantação do currículo integrado em toda a rede, foi a de, na tentativa de integração, acabar priorizando a formação profissional em detrimento de conteúdos da formação geral em suas diferentes disciplinas. Essa preocupação é expressa, principalmente pelos professores do chamado "núcleo comum" (Ensino Médio). No caso do curso de dança, algumas disciplinas dispõem de uma carga horária menor que em outras escolas (privadas) que não possuem a articulação com a educação profissional, como é o caso da disciplina de Química, conforme relato da professora em uma das reuniões observada. Porém, ainda assim, mesmo no formato integrado (que traz tais preocupações), muitos professores 
entendem que os alunos da ETEAB/ FAETEC e, mais especificamente, os do curso de dança estão tendo uma formação geral mais ampla do que em outras escolas da rede estadual que não pertencem a FAETEC. Constatamos, portanto, que a adoção do currículo integrado não prejudica a formação geral, somente a articula com a formação profissional. Desta forma, o aluno se profissionaliza e, ao mesmo tempo, tem os conhecimentos básicos necessários para o prosseguimento dos estudos no nível superior.

A articulação das diferentes áreas do conhecimento é buscada através dos temas geradores/ binômios conceituais adotados pelo curso em cada ano. Sem dúvida, tal organização faz sentido e colabora para a integração dos conhecimentos. Porém, é importante refletir atentamente sobre o assunto, de forma a evitar simplismos. Somente a articulação do conteúdo de determinada disciplina com um tema geral que norteia o curso, não garante a integração entre a formação geral e a formação profissional e, entre trabalho manual e trabalho intelectual. Para haver um ensino realmente integrado, ele tem que abranger três dimensões, conforme aponta Ramos (2007, p. 3-9):

(I) a formação omnilateral que é "a integração de todas as dimensões da vida no processo formativo"; (II) a indissociabilidade entre a educação básica e a educação profissional como possibilidade para a juventude de inserção social e de sobrevivência econômica; (III) e a integração de conhecimentos gerais e específicos como totalidade e forma de superar o positivismo e o mecanicismo das ciências.

Por outro lado, temos que admitir que o curso busca ainda contemplar um aspecto importante do ensino integrado, que é a formação humana. Constatamos com a nossa pesquisa que o curso técnico em dança da ETEAB deixa de lado uma formação instrumental, puramente técnica, comumente encontrada das escolas de dança para dar lugar a esta formação humana, que busca uma educação política, comprometida em formar jovens que transcendam a visão do senso comum e passem a ter uma visão articulada, crítica, e que saibam transmitir isso através da arte.

A "formação humana exige da escola profundas reformulações para abrigar e potencializar a riqueza e a diversidade que para ela convergem quando recebe os alunos da classe trabalhadora" (CIAVATTA; RUMMERT, 2010, p. 466). E, assim, mesmo percebendo a integração em diversos aspectos: nos temas geradores, nas reuniões de planejamento conjunto, nas coreografias apresentadas, em trabalhos interdisciplinares, nas provas integradas, há muito ainda a avançar para alcançar o objetivo da integração plena, um desafio que não é só da equipe do curso, mas da rede FAETEC como um todo. 
Assim, com base nas reflexões possibilitadas por esta pesquisa, entendemos que o curso técnico em dança da ETEAB está no caminho certo, ao incorporar a dimensão intelectual ao trabalho produtivo, buscando formar trabalhadores capazes de atuar como dirigentes e cidadãos, entendidos como seres histórico-sociais concretos, capazes de transformar a realidade em que vivem, tendo o trabalho como princípio educativo. Consideramos, portanto, que o curso se volta para a questão das humanidades, para a cultura, a arte, o pensamento crítico e a implantação do ser no mundo, ao invés de buscar a adequação e conformação desse ser no mundo como ele é, conforme a perspectiva de Ensino Integrado defendida por Leal (2011). A pesquisa nos permitiu concluir que é inegável a constatação do caminho diferenciado que o curso de dança da ETEAB está tentando construir, já tendo galgado alguns degraus importantes na escada que serve de base para alcançar a real integração. Ainda há muito a ser feito, mas esperamos que a experiência de tal curso possa servir de inspiração a outros que também perseguem o mesmo objetivo.

\section{Referências}

ADORNO, Theodor Walter. Educação e Emancipação. Trad. Wolfgang Leo Maar. São Paulo: Paz e Terra, 1995. 190 p.

BALLET DALAL ACHCAR. Centro de Arte e Cultura - Ballet Dalal Achcar. Disponível em: <http://www.dalalachcar.com.br/oficio/academia>. Acesso em: 13 de maio de 2013.

CIAVATTA, Maria. Formação integrada caminhos para a construção de uma escola para os que vivem do trabalho. [S.1]. [2011?]. Disponível em: <www.do.ufgd.edu.br/paulolima/arquivo/ept/texto\%2011.pdf>. Acesso em: 20 de janeiro de 2014.

CIAVATTA, Maria; RUMMERT, Sonia. As implicações políticas e pedagógicas do currículo na educação de jovens e adultos integrada à formação profissional. Educação e Sociedade, Campinas, v. 31, n. 111, p. 461-480, abr.-jun. 2010. Disponível em <www.scielo.br/pdf/es/v31n111/v31n111a09.pdf>. Acesso em: 20 de janeiro de 2014.

COLI, Juliana Marília. Vissi d'arte por amor a uma profissão: um estudo sobre a profissão do cantor no teatro lírico. São Paulo: Annablume, 2006. 300 p. 
ESCOLA E FACULDADE DE DANÇA ANGEL VIANNA. Escola Técnica. [Rio de Janeiro]. Disponível em: <http://www.escolaangelvianna.com.br/blog/?cat=5>. Acesso em: 13 de maio de 2013.

ESCOLA ESTADUAL DE DANÇA MARIA OLENEWA (EEDMO). História. [Rio de Janeiro]. Disponível em: <http://www.eedmo.com.br/historia01.htm>. Acesso em: 13 de maio de 2013.

ESCOLA DE DANÇA PETITE DANSE. Curso de Formação Profissional. [Rio de Janeiro]. Disponível em: $<$ http://www.petitedanse.com.br/ensino/profissional $>$. - Acesso em: 13 de maio de 2013.

ESCOLA TÉCNICA ESTADUAL ADOLPHO BLOCH (ETEAB). Plano de Curso Técnico em Dança. [Rio de Janeiro]. [Mimeo]. 2013.

ESCOLA TÉCNICA ESTADUAL ADOLPHO BLOCH (ETEAB). Projeto Político Pedagógico. [Rio de Janeiro]. [Mimeo]. 2004.

FAETEC. Novo curso técnico de dança com matriz curricular integrada na ETE Adolpho Bloch. [Rio de Janeiro]. Disponível em: <http://www.faetec.rj.gov.br/index.php?option=com_content\&view=article\&id=17 59:novo-curso-tecnico-de-danca-com-matriz-curricular-integrada-na-ete-adolphobloch\&catid=12: noticias\&Itemid=20>. Acesso em: 20 de maio de 2011 .

FEITOSA, Teresinha de Sousa. As "reformas" do ensino profissionalizante de 1996 a 2006 na Escola Agrotécnica Federal de Crato Ceará: acomodação à legislação ou consciência da prática? (Dissertação) Mestrado em Educação Agrícola - Universidade Federal Rural do Rio de Janeiro. 2010. 89 f.

FERREIRA, Ângela. Curso Profissional de Nível Técnico em Dança - o que eles formam? In: TOMAZZONI, Airton; WOSNIAK, Cristiane; MARINHO, Nirvana (Org.). Algumas perguntas sobre dança e educação. Joinville: Nova Letra, 2010.

FRIGOTTO, Gaudêncio; CIAVATTA, Maria; RAMOS, Marise. A gênese do Decreto n, 5.154/2004: um debate no contexto controverso da democracia restrita. IN: FRIGOTTO, Gaudêncio; CIAVATTA, Maria; RAMOS, Marise. Ensino Médio Integrado: concepção e contradições. FRIGOTTO, Gaudêncio (org.). São Paulo: Cortez, 2005. P. 21-56. 
LEAL, Leila. Educação Profissional e Ensino Médio Integrado no Brasil: um balanço das conquistas e reivindicações. Poli: Saúde, Educação e Trabalho, Ano III - no 15, Rio de Janeiro, p. 4-11, 2011.

MARINHO, Nirvana. Mestres de balé, escolas de bailado: uma realidade política. In: TOMAZZONI, Airton; WOSNIAK, Cristiane; MARINHO, Nirvana (Org.). Algumas perguntas sobre dança e educação. Joinville: Nova Letra, 2010.

MARQUES, Isabel. Dança-educação ou dança e educação? Dos contatos às relações. In: TOMAZZONI, Airton; WOSNIAK, Cristiane; MARINHO, Nirvana (Org.). Algumas perguntas sobre dança e educação. Joinville: Nova Letra, 2010.

NAVAS, Cássia. Centros de formação: o que há para além das academias? In: TOMAZZONI, Airton; WOSNIAK, Cristiane; MARINHO, Nirvana (Org.). Algumas perguntas sobre dança e educação. Joinville: Nova Letra, 2010.

NOGUEIRA, Monique Andries. Universidade e formação cultural dos alunos. In: GUIMARÃES, Valter Soares. (org). Formar para o mercado ou para a autonomia? Campinas: Papirus, p. 89-107, 2006.

RAMOS, Marise. Concepção do ensino médio integrado à formação profissional. Seminário sobre Ensino Médio. Superintendência de Ensino Médio da Secretaria de Educação do Estado do Rio Grande do Norte, Natal, agosto de 2007, [mimeo].

REIS, Ronaldo Rosas. Trabalho e conhecimento estético. Trabalho, Educação e Saúde, v. 2 n. 2, p. 227-250. 2004. Disponível em: <www.scielo.br/pdf/tes/v2n2/02.pdf>. Acesso em: 20 de janeiro de 2014.

SAVIANI, Demerval. O Choque Teórico da Politecnia. Trabalho, Educação e Saúde. Rio de Janeiro, v.1 (1), p. 131-152, 2003.

STRAZZACAPPA, Márcia. Políticas públicas para a Dança: um olhar sobre o ensino de Dança. In: Conhecendo e Reconhecendo a Dança na UFRJ - Anais do Seminário Interno do Departamento de Arte Corporal da Escola de Educação Física e Desportos, 5. Rio de Janeiro, 2 a 11 de dezembro de 2008. Rio de Janeiro: Universidade Federal do Rio de Janeiro, 2009.

TERRA, Ana. Onde se produz o artista da dança? In: TOMAZZONI, Airton; WOSNIAK, Cristiane; MARINHO, Nirvana (Org.). Algumas perguntas sobre dança e educação. Joinville: Nova Letra, 2010. 
VEJA RIO. 0 ninho dos cisnes. Rio de Janeiro, 16 de outubro de 2013. Cotidiano. Disponível em: <http://vejario.abril.com.br/edicao-da-semana/rotina-aulas-baleescola-de-danca-maria-olenewa-756742.shtml>. Acesso em: 10 de janeiro de 2014.

VILELA, Lilian Feitas. Alunos egressos dos cursos de graduação em dança: onde eles estão agora? In: TOMAZZONI, Airton; WOSNIAK, Cristiane; MARINHO, Nirvana (Org.). Algumas perguntas sobre dança e educação. Joinville: Nova Letra, 2010.

Recebido em 31/08/2018

Aprovado em 28/09/2018 